\title{
A unique native prefix in English language
}

\author{
Branka Mladenovic \\ Department of Linguistic, Language and Literature, Faculty of Philology, Belgrade University, Serbia
}

Email address:

bmladeno@gmail.com

\section{To cite this article:}

Branka Mladenovic. A unique Native Prefix in English Language. International Journal of Literature and Arts. Vol. 2, No. 2, 2014, pp. 29-34. doi: 10.11648/j.ijla.20140202.11

\begin{abstract}
History of English derivational system shows that only a few native prefixes, particularly negative, have survived the influx of foreign ones. There is though one native negative prefix, i.e. un- which has not only survived but has continued to be almost equally productive. The results we have got prove our assumption that it is due to different 'nature' of prefix un- in comparison with other native negative prefixes.
\end{abstract}

Keywords: Derivation, Suffixes, Prefixes, Logical/Practical Meaning

\section{Introduction}

Looking at the history of English prefixes in general and negative in particular, it can be easily noticed that only one of the native prefixes has survived almost with equal strength/productivity through all periods of English language, i.e. prefix un-.

Our intention is that through a brief history of English derivational system and the destiny of native, especially negative prefixes confirm our assumption that only its "double" structure has allowed it to survive and to be productive; for the moment, let us introduce this "double" structure in the terms of general and specific. Hence, we have followed: (i) the change of English derivational system; and (ii) the relationship between prefix un- and other negative prefixes. These two lines of our investigation have led not only to make a distinction between native and foreign negative prefixes (and foreign and native basis), but also to make a distinction between general and specific negative prefixes. While the first distinction is a common one, the second needs some explanation. Namely, we have noticed that the range of negative meaning conveyed into bases (stems) includes pure logical meaning of contrary and contradictory oppositions on one hand, which we have called general /logical, and on the other hand all other meanings, which we have called specific /practical. Similar ideas can be found in https://castl.uit.no/phocadownload/Decennium_Posters/decl ercq.pdf and references therein.

To determine the nature of negative prefixes through Old, Middle and Modern English periods, we have used two criteria, the origin of the prefix/base and the range of conveyed meaning, and got four groups of negative prefixes: general-native $(\mathrm{GN})$, general-foreign $(\mathrm{GF})$, specific-native (SN) and specific-foreign (SF). This way our list of negative prefixes in Modern English language contains seven prefixes: un-, dis-, de-, in-, a-, non- and mis-. The lists of other authors contain from five to twelve negative prefixes, i.e. in [14] and [2] the authors gave the list of 5 negative prefixes, in [10] gave 12 , or 6 as given in http://www.linglish.net/2008/09/15/so-many-negative-prefi xes/, etc.

The criterion we have also used when comparing negative prefixes, but which has no influence on our list, is the range of their application, i.e. the class of words they are added to. This criterion is used to determine the productivity of a negative prefix and not its "nature". We use the unique definitions for the basic notions like word, word formation, prefixes, and productivity as defined in [1] and Marchand[11], similarly to [8].

We have structured our paper, respecting the two lines that we follow, into three sections in accordance with usual division of the history of English Language, Old, Middle and Modern. Each section contains the presentation of derivational patterns, particularly prefixing, features of negative prefixes, and the relation between prefix un- and other negative prefixes in the particular period. The fourth section is the conclusion, where we also give some suggestions for a further research.

\section{Derivation in Old English Language}

If we define derivation as a "morphological process that results in the formation of new lexems and affixes as bound 
morphs (where those attached after and before are suffixes and prefixes, respectively)", [1: Introduction] then, we can say that derivation is the same word-formation pattern in OE, Middle and Modern English. Though, according to the existing written documents, the vocabulary in Old English (OE) augmented by 'word-formation patterns just similar' [6:100] to those in Middle and Modern English. Derivation in OE differs from derivation in other periods because it was based on a number of basic native words used to produce whole groups of new words of different classes, or with modified meaning, see [4]. Such system of derivation was possible because OE was almost a “pure' tongue, i.e. it used native material as much as possible; so, "everything was native and easily understood even for the most uneducated", [5:44]. Regarding prefixing and negative prefixes in particular, it was much easier to understand the meaning conveyed into bases than ever after.

Suffixing was the main pattern (besides compounding) to form adjectives and nouns. On the other hand, prefixing was more productive with verbs. The most frequent prefixes were: a-, be-, ge-, for-, fore-, in-, to-, under-, on-, mis-, un-, see [12:251]. The group of negative prefixes consisted of six prefixes: on-, wan-, or-, mis- and un-. They were mainly added to nouns and adjectives, and their function was to convey negative meaning into bases; prefixes un- and orwere also used to intensify the meaning of a base.

Before we compare prefix un- with other negative prefixes in $\mathrm{OE}$, we shall give some characteristic features of each of them. The examples are taken from Korac (2000).

\subsection{Features of Negative Prefixes}

In this article, three criteria are used to compare negative prefixes: meaning they convey into a base, origin of the prefix/base, and range of application used to show the level of their productivity. As in this period almost all words were of native origin, we shall apply the term native to negative prefixes.

Prefix un- could be added to all parts of speech, but was primarily added to nouns and adjectives. The range of meaning conveyed into bases included both logical and practical meaning: "not, lacking of, without, deprived of, removal, reversal of the action", as in the following example.

Example 1: unwid - not wide, unmihtan - to deprive of strength, unmurnlice - without sorrow, unscrydan - to undress.

It also conveyed pejorative meaning, as in unman and privative meaning, as in ungecveme - unpleasing. As mentioned in 2, it could intensify the meaning of the base, as in limp - accident and unlimp - misfortune.

When attached to simple verbs, both strong and weak, it conveyed the meaning of "reversal of the action", as in: unbindan - loosen, unlucan - to unlock, ungierwan - to unclothe, undon - open, loosen, separate. Attached to a small group of verbs ending in -ian, it conveyed the meaning of "deprived of, remove", as in: unhadian - divest of holy order, unaedelian - to degrade, debase, uninseglian - to unseal.

Prefix on - presents an unstressed form of prefix un-. It was used in early and late OE; in Middle English, both variants were used so as in early Modern English.

Prefix wan - was predominantly attached to nouns, although it could be added to adjectives and verbs, as in the following example.

Example 2. wandian - to hesitate; wansceaft - misery; wanhal - sick.

It conveyed specific/practical meaning in the sense of "lacking of, without" as in: wana - lack, want, deficiency; wanhaelan - to weaken. It also conveyed privative meaning, as in wandung - feeling of respect. There were a considerable number of words formed with this prefix, but none has survived into Modern English, and only one into Middle English, i.e. wansthed - ill-success.

There was prefix won-, whose destiny was closely connected to wan- and which is considered to be a kind of wan- variant. We could not find more details about them or about their origin.

Prefix mis- was predominantly added to verbs, participles and nouns of action and condition.

Example 3. misbeodan - ill treat; misbyrd - abortion.

Very rarely, it was added to adjectives and adverbs. It conveyed specific/practical meanings like "wrongly, improperly"

Prefix or- was predominantly attached to nouns, rarely to adjectives and adverbs, conveying specific/practical meaning of "without, void of, bereft of" as in: ortriewan - to despair; ormodness - despair. It conveyed privative meaning, as in orsorg - unconcern. Its other function was to intensify the meaning of the base, as in oreald - very old. Words prefixed with or- survived till early period of Middle English, though the only meaning conveyed was "without".

\subsection{Comparison}

To determine productivity of native prefixes, we have compared them with respect to: 1) range of negative meaning conveyed into (native) bases and 2) range of application.

1) Range of negative meaning conveyed into bases

\begin{tabular}{lllll}
\hline prefix & G/LN & G/LF & S/PN & S/PF \\
\hline un- & $\mathrm{x}$ & & $\mathrm{x}$ & \\
wan- & & $\mathrm{x}$ & \\
or- & & $\mathrm{x}$ & \\
mis- & & $\mathrm{x}$ & \\
\hline
\end{tabular}

It is obvious that only prefix un- conveys general/logical meaning into bases. Regarding specific/practical (S/P) meanings:

un - conveys: "lacking of, without, deprived of, removal, and reversal of the action";

wan- conveys: "lacking of, without";

or - conveys: "without, void of, bereft";

mis - conveys: "wrongly, improperly". 
So, prefix un - competed with wan- and or- but not with mis- . Its range of specific meaning though, exceeds the range of all other native negative prefixes.

2) Range of application

\begin{tabular}{lllll}
\hline prefix & nouns & adjectives & verbs & adverbs \\
\hline un- & $\mathrm{x}$ & $\mathrm{x}$ & $\mathrm{x}$ & \\
wan- & $\mathrm{x}$ & $\mathrm{x}$ & $\mathrm{x}$ & \\
or- & $\mathrm{x}$ & rarely & & rarely \\
mis- & $\mathrm{x}$ & rarely & $\mathrm{x}$ & rarely \\
& & & & \\
\hline
\end{tabular}

As we can see, prefix un- can be attached to almost all parts of speech except adverbs, so as wan- while other prefixes are mainly added to nouns. Prefix un- competed only with mis- when verbs are in question. The recorded number of words prefixed with un-, 1250 words prefixed with un- [11: 153], expresses its high productivity.

\section{Derivation in Middle English}

A feature common for all three periods of Middle English (MdE), see [13] for details, is the great impact of foreign languages, primarily French and Latin. Scandinavian words though always present in OE started now to enter into English literature and to prevail over the corresponding native words, i.e. die - steorfan, or sky - heofan; some function words were fully adopted, like they, their, them so as some derivational patterns, like suffix -t, as in scan-t. Yet, these loans were not numerous and in a way, were familiar. On the other hand, French words were strange and came as a flood into OE.

The coherent system of native words in OE, and derivational patterns based on it, were totally shaken. "The language took to wholesale borrowing, a method which meant an enormous cut-down on the traditional patterns of word-formation out of native material", [11:86]. The majority of borrowings were nouns, at first of common core of French vocabulary, and later, of more abstract nature, [7:141]. These abstract nouns brought new suffixes and prefixes into English Language.

Suffixing was more productive than prefixing because some Romance suffixes, such as -able, -age, -al and -ard, were soon fully adopted and used with native bases, see [7:147-155]. On the other hand, an enormous cut-down on native bases caused enormous cut-down in productivity of prefixing. Native prefixes could not coin with foreign bases, and foreign prefixes were not used as derivational morphs till the period of Renaissance. At the end of ME period, only a few native prefixes (of more than 30, see [7:147-155]) remained, i.e. be-, for-, fore-, mis- and un-. New foreign prefixes were: super-, sub-, re-, em-, en-, and a group of negative prefixes, i.e. dis-, in-, de-.

\subsection{Features of Negative, Native and Foreign, Prefixes}

Prefix mis- survived and was productive because, having similar form and meaning, it merged with corresponding Old French (OF) prefix mes-/me- . So, the borrowed words were easily adjusted. It was added to verbs and verbal nouns (as in $\mathrm{OE}$ ), and being strengthen by mes-, it produced numerous new nouns and verbs, like miskonforten - discomfort, mispaine - displease.

Prefix un- did not merge with any foreign prefix but did not share the destiny of other native negative prefixes, either. Though the great number of native words prefixed with undisappeared, it survived while wan-, won- and ordisappeared along with the disappearance of the native bases they were coined with. It started very soon to coin with foreign bases, as in unprofit, unpeasible or uncofre. It continued to coin with all parts of speech, but more with adjectives and past participles as adjectives than with nouns. It conveyed logical meaning of "not" and practical meanings "deprived of, without, lacking of" when coined with adjectives and nouns, and mainly "reversal of the action" when coined with verbs.

Prefix dis- was introduced by OF loans, which were mainly verbs. It coined with all parts of speech. When coined with verbs, both denominal and deverbal, it conveyed meanings of "not, deprive of, reversal of the action", as in dislike, dishonor, dismantle, respectively. When coined with nouns, it conveyed meanings of "not, lacking of, without, reversal" as in dissimilar, dishonest, displeasure, disproportion. It also coined with adjectival bases, all of which were of Romance origin, as in dissatisfactory, discreditable, dissocial. In Modern English, it is primarily used with verbs and abstract nouns.

Prefix in- (its allomorphs il-, ir-, im-) was used with adjectives and nouns of Latin and French origin; then it conveyed logical meaning of "not", as in incompatible, incompetent etc. Coined with nouns, it conveyed practical meanings of " lacking of, absence", as in inaccuracy, incompetence. It is always coined in accordance with the rules of Latin language. In Modern English it is of marginal productivity.

\subsection{Comparison}

To determine productivity of native prefixes, we have compared them with respect to: 1) range of negative meaning conveyed into (native and foreign) bases and 2) range of application.

1) Range of negative meaning conveyed into bases

\begin{tabular}{lllll}
\hline prefix & G/LN & G/LF & S/PN & S/PF \\
\hline mis- & & & $\mathrm{x}$ & $\mathrm{x}$ \\
un- & $\mathrm{x}$ & $\mathrm{x}$ & $\mathrm{x}$ & $\mathrm{x}$ \\
dis- & & $\mathrm{x}$ & & $\mathrm{x}$ \\
in- & & $\mathrm{x}$ & & $\mathrm{x}$ \\
\hline
\end{tabular}

Now we have three negative prefixes which convey logical meaning, un-, dis-", and in-". Regarding specific/practical (S/P) meanings:

un- conveys: "lacking of, without, deprived of, reversal of 
the action";

mis - conveys: "wrongly, improperly";

dis- conveys: "lacking of, without",

in- conveys: "lacking of, absence".

As can be noticed, prefix un- still has much broader range of meaning than any other negative prefix although it lost the meaning of "removal". It conveys logical and practical meanings into both native and foreign bases.

2) Range of application

\begin{tabular}{lllll}
\hline prefix & nouns & adjectives & verbs & adverbs \\
\hline mis- & $\mathrm{x}$ & & $\mathrm{x}$ & \\
un- & rarely & $\mathrm{x}$ & $\mathrm{x}$ & \\
dis- & $\mathrm{x}$ & $\mathrm{x}$ & $\mathrm{x}$ & \\
in- & $\mathrm{x}$ & $\mathrm{x}$ & & \\
\hline
\end{tabular}

It is interesting that prefix un- was rarely added to nouns, but the explanation is simple, the majority of nouns were now borrowed from French or Latin; hence dis- and inprevailed.

Prefix in- conveyed logical meaning when added to adjectives, and when added to nouns, conveyed only practical meanings. Prefix dis- conveyed both meanings whichever part of speech it was added to. Detailed analysis on productivity of these prefixes in all periods of Middle English can be found in [9].

\section{Derivation in Modern English}

The great number of borrowed words, particularly abstract nouns, foreign derivational affixes, patterns and functional words was the heritage of MdE. The process of borrowings continued but now only "the parts of words, affixes, of which some are prefixes, and some suffixes" were borrowed, [12:26]; these 'parts' mainly came from Greek and Latin. It resulted in total number of 41 prefixes, and 61 suffixes, see [3:26-28]. In this situation, the vocabulary of Modern English augmented enormously, but with few exceptions classical roots serve to express even simple ideas, see [5:43]. Suffixing is still more productive with nouns and adjectives, and prefixing is more productive with verbs, see [12:41]. Regarding negative prefixes, Modern English got additional three new ones, i.e. a-, de-, non-.

\subsection{Features of Native and Foreign Negative Prefixes}

Prefix a- presents the Greek prefix a-. English coinage are all derivatives from nominal bases but are practically interpreted as opposites of unprefixed adjectives. Its domain of practical usage is mainly restricted to medical area, with only a few words in common use, i.e. amoral, atonal atemporal and asymmetric. It conveys logical and practical meanings of "not, without, devoid of".

Prefix non- originates from Latin Law, i.e. from the model non-creditor used for coining new nouns. Today, it can be prefixed to almost any adjective, present and participles used as adjectives, as in non-active, non-breakable, non-competent, non-analysed, non-interrupted, [1:279). It shows immense productivity, but can not be used with verbs. It conveys only logical meaning into bases.

Prefix de- has always formed denominal verbs with privative meaning, and deverbal verbs with reversative meaning in French. Its range of application is restricted to verbs, mainly denominative, as in defrost, dethrone, defrock. It conveys logical meaning as in debate, and practical of "remove from, diminish", as in dehydrate, demolish, depreciate.

Prefix un- competes with non- when adjectives are in question, and it seems that non- pattern is becoming more productive. Regarding verbs, it is more productive than prefix de- when conveying the meaning "reversal", but has lost when conveying the meaning of "deprived of", as in decapitate, defraud.

\subsection{Comparison}

1) Range of meaning

\begin{tabular}{lllll}
\hline prefix & G/LN & G/LF & S/PN & S/PF \\
\hline mis- & & & $\mathrm{x}$ & $\mathrm{x}$ \\
un- & $\mathrm{x}$ & $\mathrm{x}$ & $\mathrm{x}$ & $\mathrm{x}$ \\
dis- & & $\mathrm{x}$ & & $\mathrm{x}$ \\
in- & & $\mathrm{x}$ & $\mathrm{x}$ \\
a- & & $\mathrm{x}$ & & $\mathrm{x}$ \\
non- & $\mathrm{x}$ & $\mathrm{x}$ & & \\
de- & $\mathrm{x}$ & $\mathrm{x}$ & $\mathrm{x}$ & $\mathrm{x}$ \\
\hline
\end{tabular}

All foreign negative prefixes convey logical meaning into bases, but obviously only two negative prefixes, un- and decompete when range of meaning is in question. Regarding specific/practical (S/P) meanings:

un - conveys: "lacking of, without, deprived of, reversal of the action";

mis - conveys: "wrongly, improperly";

dis - conveys: "lacking of, without",

in - conveys: "lacking of, absence",

a - conveys: "without, devoid of",

non - no practical meaning

de - conveys: "diminish, removal"

2) Range of Application

\begin{tabular}{lllll}
\hline prefix & nouns & adjectives & verbs & adverbs \\
\hline mis- & $\mathrm{x}$ & & $\mathrm{x}$ & \\
un- & rarely & $\mathrm{x}$ & $\mathrm{x}$ & \\
dis- & $\mathrm{x}$ & $\mathrm{x}$ & $\mathrm{x}$ & \\
in- & $\mathrm{x}$ & $\mathrm{x}$ & & \\
a- & & $\mathrm{x}$ & \\
non- & $\mathrm{x}$ & $\mathrm{x}$ & \\
de- & & & $\mathrm{x}$ \\
\hline
\end{tabular}


When range of application is in question, really strong opponent to prefix un- is non-, but it can not be added to verbs.
If we summarize the results, we get the following table (prefixes dis- and in- are omitted in the section Modern English only to avoid duplicating the data):

Table 1. Two criteria comparison of all negative prefixes

\begin{tabular}{|c|c|c|c|c|c|}
\hline \multicolumn{6}{|c|}{ Old English period } \\
\hline \multirow[t]{2}{*}{ Prefix } & \multicolumn{4}{|c|}{ Range of application } & Meaning(G/P); \\
\hline & $\mathrm{N}$ & A & $\mathrm{V}$ & Av. & Prefix/base origin $(\mathrm{N} ; \mathrm{F})$ \\
\hline Un- & $\mathrm{xx}$ & $\mathrm{xx}$ & $\mathrm{x}$ & $\mathrm{x}$ & $\begin{array}{l}\text { N: G-Not; P-deprive, lacking, without, removal, reversal of the } \\
\text { action }\end{array}$ \\
\hline Wan- & $\mathrm{xx}$ & $\mathrm{x}$ & $\mathrm{x}$ & & $\mathrm{N}$ : P-lacking of, without \\
\hline Or- & $\mathrm{xx}$ & $-\mathrm{x}$ & & $-\mathrm{x}$ & N: P-without, void of, bereft of \\
\hline Mis- & $\mathrm{x}$ & $-\mathrm{x}$ & $\mathrm{xx}$ & $-\mathrm{x}$ & $\mathrm{N}:$ P-wrongly, improperly \\
\hline \multicolumn{6}{|c|}{ Middle English } \\
\hline Un- & $-\mathrm{x}$ & $\mathrm{xx}$ & $\mathrm{xx}$ & & N/NF G-Not; P-deprive, without, lacking, reversal of the action \\
\hline Mis- & $\mathrm{x}$ & & $\mathrm{xx}$ & & N/NF: P-wrongly, improperly \\
\hline Dis- & $\mathrm{xx}$ & $\mathrm{x}$ & $\mathrm{xx}$ & & F/F G-Not; P-deprive, reversal of the action, lacking, without \\
\hline In- & $\mathrm{xx}$ & $\mathrm{xx}$ & & & $\begin{array}{l}\text { F/F: G- (with adjectives) Not,; } \\
\text { P-(with nouns) lacking, absence }\end{array}$ \\
\hline \multicolumn{6}{|c|}{ Modern English } \\
\hline Un- & $-\mathrm{x}$ & $\mathrm{xx}$ & $\mathrm{x}$ & & N/NF: G-Not; P-lacking, deprive, without, reversal of the action \\
\hline Mis- & $\mathrm{x}$ & & $\mathrm{xx}$ & & N/NF:P-wrongly, improperly \\
\hline A- & & $\mathrm{xx}$ & & & F/F: G-Not; P-without, devoid \\
\hline Non- & $\mathrm{x}$ & $\mathrm{xx}$ & & & $\mathrm{F} / \mathrm{FN}:$ \\
\hline De- & & & $\mathrm{xx}$ & & F/F: G-Not; P-remove from, diminish, deprive of \\
\hline Legend & Primarily & $\mathrm{xx}$ & Less & $\mathrm{x}$ & Rarely \\
\hline
\end{tabular}

\section{Conclusion}

Two main conclusions can be drawn from Table 1. The first is: all native negative prefixes, except un-, convey only P-meaning into bases. The second, all foreign negative prefixes (including Old French me- and mes-, which gave new strength to native mis-), except non- convey both $\mathrm{G}$ and $\mathrm{P}$ meanings into bases, which are mainly foreign. This confirms our assumption that double nature of prefix un- has allowed it to survive and compete with foreign negative prefixes, and to coin with foreign bases. This also explains why native negative prefix mis- is not productive any more. Hence, the most important feature of a negative prefix is its ability to convey a kind of logical meaning into a base. Having this in mind, we can also make some further assumptions regarding the productivity of prefix non-. Namely, as it conveys only logical meaning into bases, it means that it can coin with basis of all origins and that it will become more and more productive regarding adjectives and even nouns. This means that prefix un- will survive but much more constrained, and probably prefix non- will gain the same position as prefix unhad in $14^{\text {th }}$ century, see [12:195]. This brings us back to the problem why native negative prefixes did not survive. It is obvious that los of native words cannot be the only reason. Namely, strictly practical meaning they could convey did not allow them to coin with foreign bases. As for future work, it would be interesting to follow the destiny of un- in comparison with non- patterns.

\section{References}

[1] L.Bauer, (1983). English Word Formation. Cambridge: University Press.

[2] D.Crystal, (2003). The Cambridge Encyclopedia of the English Language. Cambridge: University Press.

[3] R. Djordjevic, (1997). Grammar of English Language (second edition), Belgrade: Author. Gramatika Engleskog jezika (drugo izdanje), Beograd: Autor.

[4] J.R.C. Hall, (1960). A Concise Anglo-Saxon Dictionary. Cambridge: University Press.

[5] O. Jespersen, (1948). Growth and Structure of the English Language. Oxford: Basil, Blackwell.

[6] G. Korac, (2000). An Outline of Old English Grammar. Belgrade: The Institute for Foreign Languages.

[7] G. Korac, (2002). An Outline of Middle English Grammar. Beograd: Filoloski fakultet, Narodna Knjiga.

[8] A. Lehrer, (2009). "Prefixes in English Word Formation". Folia Linguistica XXIX/1-2 (C), pg. 133-148, Mouton de Gruyter, Berlin.

[9] U. Lutzky, (2004). "Negative prefixes in Middle English: a corpus based study of dis-, in-, mis-\&un-“, Vienna English Working Papers, Vol.13, No.2, 24-52.

[10] J. at all. March, (2003). "Negative prefixes can be positively confounding". Edit Prosmarketing Communications, 7(7). 
[11] H. Marchand, (1960). The Categories and Types of Present-Day English Word-Formation. Wiesbaden: Otto Harrassowitz.

[12] B. Strang, (1970). A History of English. London and Colhester: Methuen\&CoLtd.
[13] J. Wright, and E.M.Wright (1928). An Elementary Middle English Grammar. Oxford: University Press.

[14] K.E. Zimmer, (1964). "Affixal Negation in English and Other languages: An Investigation of restricted Productivity". Suppl. WORD, 20(2):5. 